\title{
Performance Enhancement of Load Frequency Controller in an Islanded Microgrid using Coefficient Diagram Approach
}

\author{
S Abhishek ${ }^{1} \mid$ Dr. Sujatha Balaraman ${ }^{2}$
}

${ }^{1}$ PG Scholar, Department of EEE, Government College of Technology, Coimbatore, Tamil Nadu, India ${ }^{2}$ Associate Professor, Department of EEE, Government College of Technology, Coimbatore, Tamil Nadu, India

\section{To Cite this Article}

S Abhishek and Dr. Sujatha Balaraman, "Performance Enhancement of Load Frequency Controller in an Islanded Microgrid using Coefficient Diagram Approach", International Journal for Modern Trends in Science and Technology, 6(8): 92-99, 2020

Article Info

Received on 18-June-2020, Revised on 09-July-2020, Accepted on 27-July-2020, Published on 04-August-2020.

\section{ABSTRACT}

This paper presents the design of a load frequency controller (LFC) using coefficient diagram method (CDM) in a multi-area power system. The CDM controller has been designed in order to reduce effect of the vagueness as a result of governor and turbine parameters variation and load disturbance. Single-area and two-area power system frequency dynamic paradigms are modelled, as well as the physical constraints of the governors and turbines are considered. MATLAB/Simulink simulations for a single area power system and two area power system are performed to validate the effectiveness of the proposed scheme. From the simulation results it is confirmed that the proposed CDM technique, gives enhanced performance under load disturbances and constraints in the parameters. Performance comparison is made between the proposed $C D M$ controller and an integral controller which affirms the upside of the proposed CDM method.

KEYWORDS: coefficient diagram method, integral control, load frequency control

\section{INTRODUCTION}

Microgrids have been introduced due to the current increase in the distributed generations, renewable resources and storage systems. Microgrids can operate either in grid connected or islandedmode. They are more advantageous because of reduction in greenhouse gases, power loss reduction etc. Conventional power sources are replaced by distributed generation sources and renewable sources such as small thermal plants, microturbines, solar etc. $[1,2]$, but as the amount of renewable energy sources increase it raises concern about the stability, reliability of microgridsbecause of the intermittent nature of such sources can cause mismatch of generated and load power which could lead to frequency deviations. Load frequency control (LFC) $[3,4]$ becomes a momentous function of power system operation where the foremost objective is to normalize the power output of every generator at desired levels by maintaining the frequency fluctuations within pre-specified limits. Today, control system designers are attempting to apply diverse control calculations so as to locate the best controller boundaries to get ideal arrangements. Fixed boundary controllers, for example, a fundamental controller or a corresponding essential (PI) controller, is likewise broadly utilized in the LFC application [5-7]. Fixed boundary 
controllers are planned at apparent working focuses, and may not, at this point be reasonable in every single working condition. For this reason, adaptive gain forecast approaches have been planned for LFC synthesis. This method overpowers the disadvantages of the conventional Proportional Integral and Derivative (PID) controllers which need adaptation of controller parameters. However, it faces some difficulties such as instability of transient response as a result of unforeseen changes in the system parameters.Load frequency control strategy based on coefficient diagram method (CDM) $[9,10]$ is developed. This strategy is an algebraic approach applied to a polynomial loop; coefficient diagram is used as the vehicle to convey the vital design material. The simulation results demonstrated that the CDM controller can be applied effectively to the utilization of power system load frequency control. In islanded mode of operation, a microgrid is capable of supplying power to the load but in case of any load fluctuations, it could lead to some serious problems if there is any mismatch between the generated power and load demand which would lead to frequency fluctuations thereby leading to blackout of the system [15]. In this paper, the load frequency control for a solitary and two area power system has been created based on the CDM method $[7,8]$. The boundaries of the polynomials of CDM procedure have been structured dependent on the dynamic model of the single and two area power system. Generation rate constraint (GRC) and speed governor dead band physical constraints are also considered. Computer simulations have been carried out to test the proposed CDM technique on the multi-area power system $[11,12]$ considering the uncertainties due to governor and turbine parameters variation and load disturbance. A correlation has been made between the CDM and the fundamental integral controller affirming the predominance of the proposed CDM procedure [10]. The simulation results demonstrated that the proposed controller can be applied effectively to the utilization of power system load frequency control. The rest of the paper is organized as follows: the description of the dynamics of a single area system (islanded microgrid) is given in section II. A universal contemplation about $\mathrm{CDM}$ is presented in section III. The implementation scheme of a single and two area power system together with the CDM technique is described in section IV. Simulation results and general observations are presented in section V. Section VI concludes the paper.

\section{II.SYSTEM DYNAMICS}

This In this section, a basic frequency response model for a single area power system with an aggregated generator unit is described [13].

The overall generator-load dynamic association betweenthe incremental mismatch of power $[10,15]$.

$$
\text { s. } \Delta \mathrm{f}=\left(\frac{1}{2 \mathrm{H}}\right) \Delta \mathrm{P}_{\mathrm{m}}-\left(\frac{1}{2 \mathrm{H}}\right) \Delta \mathrm{P}_{\mathrm{l}}-\left(\frac{\mathrm{D}}{2 \mathrm{H}}\right) \Delta \mathrm{f}
$$

The governor dynamics is expressed as:

$$
\text { s. } \Delta \mathrm{P}_{\mathrm{m}}=\left(\frac{1}{\mathrm{~T}_{\mathrm{t}}}\right) \Delta \mathrm{P}_{\mathrm{g}}-\left(\frac{1}{\mathrm{~T}_{\mathrm{t}}}\right) \Delta \mathrm{P}_{\mathrm{m}}
$$

and the dynamics of the turbine is articulated as:

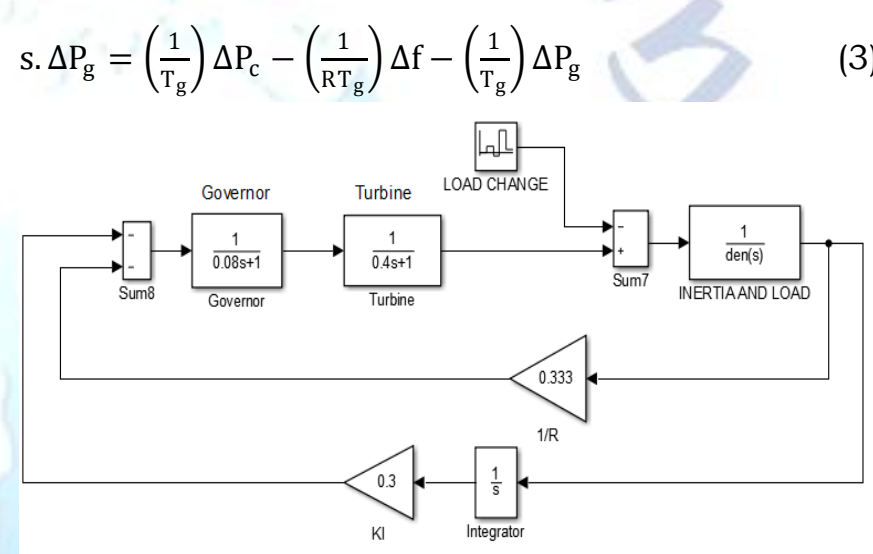

Figure 1. Block Diagram of Single Area Power System with AGC

\section{COEFFICIANT DIAGRAM METHOD}

The classical and modern control are primarily used in the design of control system. There is a third method generally called as algebraic design approach. The Coefficient Diagram Method (CDM) is one among the algebraic style approaches wherever the coefficient diagram is employed instead of Bode diagram[9]. The CDM could be a technique to rearrange the poles of a closed loop transfer function, so as to induce needed response within the time domain $[9,11]$. Coefficient Diagram provides knowledge to know the time reaction and strength attributes of frameworks in a solitary graph, which is significant for frameworks with large characteristic polynomial degree. Logarithmic vertical axis displays the coefficients of characteristic polynomial $\left(a_{i}\right)$, stability indices $\left(\gamma_{i}\right)$ and equivalent time constant $(\tau)$ whereas the horizontal axis displays the order (i) values corresponding to each coefficient in coefficient diagram. The level of convexity acquired from 
coefficients of the trademark polynomial proportion of dependability, though the overall tendency of the bend gives the proportion of the speed of reaction. The state of the curve is because of plant's boundary variety gives a measure of robustness. The block diagram ofsingle input single output (SISO) linear time invariant system with $\mathrm{CDM}$ control [10-12] is shown in Fig.2, where

$N(s)$ is numerator polynomial.

$D(s)$ is denominator polynomial. $R(s)$ is forward denominator polynomial. $F(s)$ and $T(\mathrm{~s})$ are reference numerator and feedback numerator polynomials.

In this technique,ris taken as the reference input to the system,uas the controller signal,das the outside disturbance signal and yis denoted as the output of the control system [9].

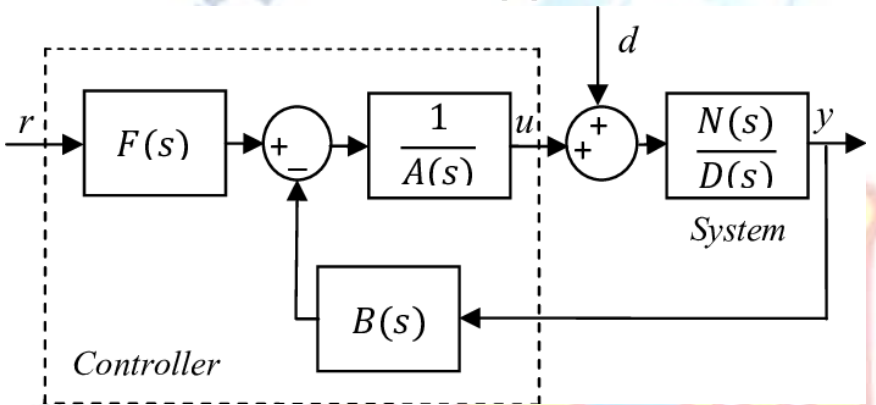

Fig 2: Block Diagram of CDM Control System.

The linear time-invariant SISO plant transfer function is expressed as:

$H(s)=\frac{a_{m} s^{m}+a_{m-1} s^{m-1}+\cdots+a_{1} s+a_{0}}{b_{n} s^{n}+b_{n-1} s^{n-1}+\cdots+b_{1} s+b_{0}}(5)$

In this technique, $d$ is taken as the peripheral disturbance signal; $r$ is taken as the reference input; $u$ is the controller signal; and $y$ is the output of the CDM control system which given by:

$y(s)=\frac{N(s) F(s)}{P(s)} r+\frac{A(s) N(s)}{P(s)} d(6)$

Where $P(s)$ can be defined as:

$$
\begin{aligned}
P(s)= & \frac{N(s) F(s)}{y} r+\frac{A(s) N(s)}{y} d(7) \\
& =R(s) D(s)+T(s) N(s)(8)
\end{aligned}
$$

Where $R(\mathrm{~s})$ and $T(\mathrm{~s})$ are taken as the control polynomial and is defined as:

$\mathrm{R}(\mathrm{s})=\sum_{\mathrm{i}=0}^{\mathrm{p}} \mathrm{l}_{\mathrm{i}} \mathrm{s}^{\mathrm{i}}$
$\mathrm{T}(\mathrm{s})=\sum_{\mathrm{i}=0}^{\mathrm{q}} \mathrm{k}_{\mathrm{i}} \mathrm{s}^{\mathrm{i}}$

Since li and Ki are CDM controller parameters. The closed loop actuating signal $u$ is:

$\mathrm{u}=\frac{\mathrm{D}(\mathrm{s}) \mathrm{F}(\mathrm{s})}{\mathrm{P}(\mathrm{s})} \mathrm{r}+\frac{\mathrm{A}(\mathrm{s}) \mathrm{D}(\mathrm{s})}{\mathrm{P}(\mathrm{s})} \mathrm{d}(11)$

To attain the characteristic polynomial $P(s)$, the controller polynomials from Eq. (9) and (10) are substituted in Eq. (8) and is given as:

$\mathrm{P}(\mathrm{s})=\sum_{\mathrm{i}=0}^{\mathrm{p}} \mathrm{l}_{\mathrm{i}} \mathrm{s}^{\mathrm{i}} \mathrm{D}(\mathrm{s})+\sum_{\mathrm{i}=0}^{\mathrm{q}} \mathrm{k}_{\mathrm{i}} \mathrm{s}^{\mathrm{i}} \mathrm{N}(\mathrm{s})$

CDM controller designing requires some specific parameters in regard to the characteristic polynomial coefficients such as the equivalent time constant $(\tau)$, the stability indices $\left(\gamma_{i}\right)$, and the stability limits $\left(\gamma_{i}{ }^{*}\right)[9,11]$. The relations between these parameters and the coefficients of the characteristic polynomial (ai) are described as follows:

$\gamma_{i}=\frac{a_{i}^{2}}{a_{i+1} a_{i-1}}, i \in[1, n-1]$

The relationship between the equivalent time constant $(\tau)$, and the actuating signal is that the time response reduces and the scale of the actuating signal becomes smaller for larger values of $\tau$. Therefore, selection of suitable time equivalent constant $(\tau)$ is one amongst the vital steps within the design procedure. Equivalent time constant $(\tau)$ and stability indices $\left(\gamma_{i}\right)$ are chosen as:

$\tau=\frac{\tau_{\mathrm{s}}}{2.5 \approx 3}(14)$

Where $\tau_{s}$ is the user specified settling time.

The target characteristic polynomial can be obtained by rewriting the characteristic polynomial in equation (8) as per the relation between key parameters $(\tau, \gamma \mathrm{i})$ and $a_{0}$ :

$\mathrm{P}_{\text {target }}=\mathrm{a}_{0}\left[\left\{\sum_{\mathrm{i}=2}^{\mathrm{n}}\left(\prod_{\mathrm{j}=1}^{\mathrm{i}-1} \frac{1}{\gamma_{\mathrm{i}-\mathrm{j}}^{\mathrm{j}}}\right)(\tau \mathrm{s})^{\mathrm{i}}\right\}+\tau \mathrm{s}+1\right]$

Where,

$$
\begin{aligned}
& P(s)=P_{\text {target }}(s) \\
& \gamma_{i}=[2.5,2,2 \ldots]
\end{aligned}
$$

Where $y_{i}$ are the stability indices.

Also, the reference numerator polynomial $\mathrm{F}(\mathrm{s})$ can becalculated from:

$\mathrm{F}(\mathrm{s})=\frac{\mathrm{P}(\mathrm{s})}{\mathrm{N}(\mathrm{s})}(16)$ 


\section{SYSTEM CONFIGURATION}

The block diagram of a frequency response paradigm of a single area power system with the proposed CDM controller [9] is shown in Fig. 3. The system comprises of the rotating mass and load, turbine, and governor [13]. The frequency deviation is employed as feedback for the closed loop-control system. The measured and reference frequency deviation $\Delta \mathrm{fand}$ the reference frequency $(\Delta \mathrm{f}=\mathrm{OHz})$ are fed to the CDM in order to obtain the supplementary control action $\Delta \mathrm{P}_{\mathrm{c}}$, which add to the negative frequency feedback signal. The resulting signal $\Delta \mathrm{P}_{\mathrm{c}}$ is fed the governor giving the governor valve position which supplies the turbine to give the mechanical power change $\Delta \mathrm{P}_{\mathrm{c}}$, which is affected by the load change $\Delta \mathrm{P}_{\mathrm{c}}$, giving the input to the rotating mass and load block in order to provide actual frequency deviation $\Delta \mathrm{f}[14,15]$.

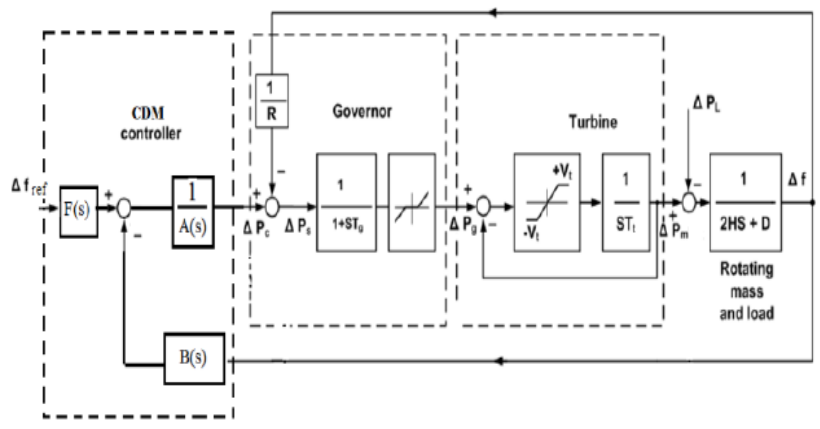

Figure 3: Block Diagram of Single Area Power System with CDM Controller

Two area interconnected power system $[8,11]$ having the following parameters as listed in table 2 .

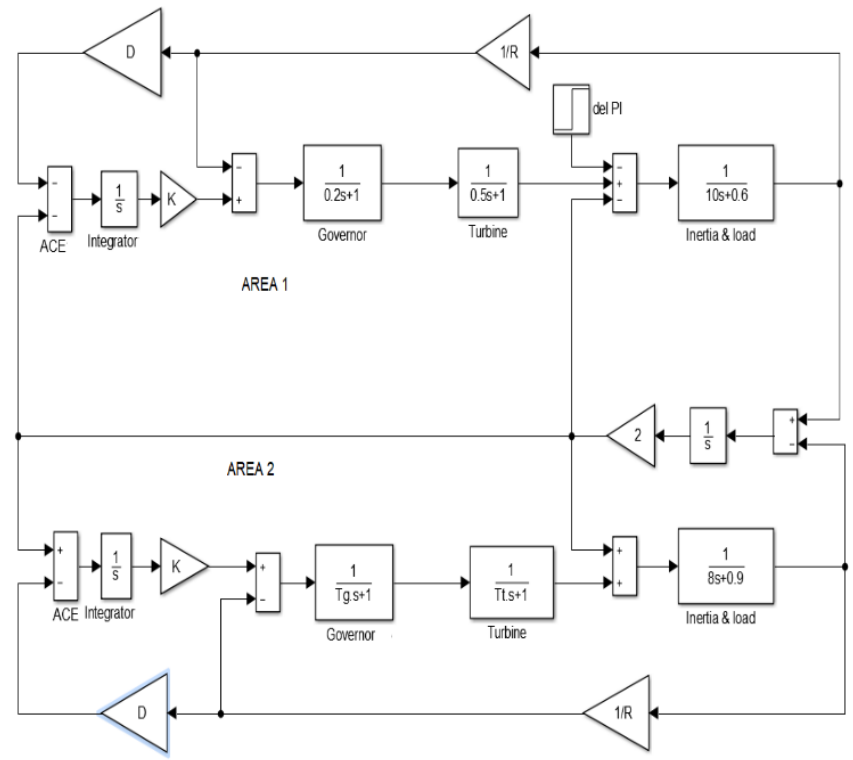

Figure 4: Block Diagram of Two Area Power System with Integral Controller

\section{V.SIMULATION RESULTS}

Computer simulations have been carried out in order to corroborate the effectiveness of the projected system. The MATLAB/Simulink software has been used for this purpose.

The parameters chosen for a single area power system as listed in table 1.

Table1.Parameters of single area power system

\begin{tabular}{|l|l|l|l|l|}
\hline $\mathrm{D}($ p.uHz) & $\begin{array}{l}\mathrm{H} \\
\text { (p.u.sec) }\end{array}$ & $\begin{array}{l}\mathrm{R} \\
(\mathrm{Hz} / \text { p.u. })\end{array}$ & $\begin{array}{l}\mathrm{T}_{\mathrm{g}} \\
(\mathrm{sec})\end{array}$ & $\begin{array}{l}\mathrm{T}_{\mathrm{t}} \\
(\mathrm{sec})\end{array}$ \\
\hline 0.015 & 0.08335 & 3 & 0.08 & 0.4 \\
\hline
\end{tabular}

CDM controller parameters are set as follows: The objective of the controller is to achieve the desired performance within the bound of the disturbance. According to the values of microgrid parameters in table 1 . The closed loop transfer function of the plant model of single area system [13] can be defined as follows:

$$
\begin{gathered}
\mathrm{N}(\mathrm{s})=0.032 \mathrm{~s}^{3}+0.48 \mathrm{~s}^{2}+\mathrm{s} \\
\mathrm{D}(\mathrm{s})=5.33 \mathrm{e}^{-3} \mathrm{~s}^{4}+0.08 \mathrm{~s}^{3}+0.174 \mathrm{~s}^{2}+0.348 \mathrm{~s}-0.3
\end{gathered}
$$

the CDM controller polynomials are chosen in the form of equation (9) and (10) respectively, the stability indices are taken as per Manabe's standard [9] form

$\mathrm{P}$ target is formed as per equation (12)

$$
P_{\text {target }}=0.0128 s^{5}+0.128 s^{4}+0.64 s^{3}+1.6 s^{2}+2 s+1
$$

$\mathrm{A}(\mathrm{s})$ and $\mathrm{B}(\mathrm{s})$ is obtained after substituting $\mathrm{N}(\mathrm{s})$ and $\mathrm{D}(\mathrm{s})$ in equation (12) and compared with $\mathrm{P}$ target to obtain the corresponding coefficients of $\mathrm{A}(\mathrm{s})$ and $\mathrm{B}(\mathrm{s})$;

$$
\begin{gathered}
\mathrm{R}_{\mathrm{i}}=2.4 \mathrm{~s}^{4}+2.77 \mathrm{~s}+0.008 \\
\mathrm{~T}_{\mathrm{i}}=\mathrm{s}^{2}+1.036 \mathrm{~s}+1
\end{gathered}
$$

An islanded microgrid (single area system) is considered whose block diagram is shown in Figure 1 , and is tested using CDM and conventional controller.

\section{CASE 1:}

In this case, the performance analysis of the single area power system is done with CDM controller and integral controller $\mathrm{Ki}=-0.3$ with step load changes $\Delta \mathrm{P}_{1}$ as shown in Figure 5 . Figure 6 
shows the simulation results of the proposed CDM controller and integral controller.

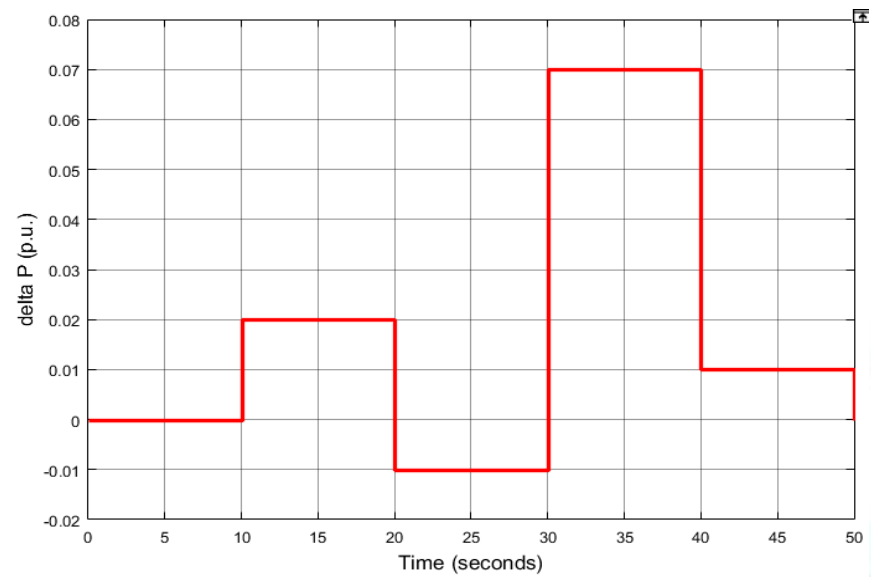

Figure 5: Random Load Demand

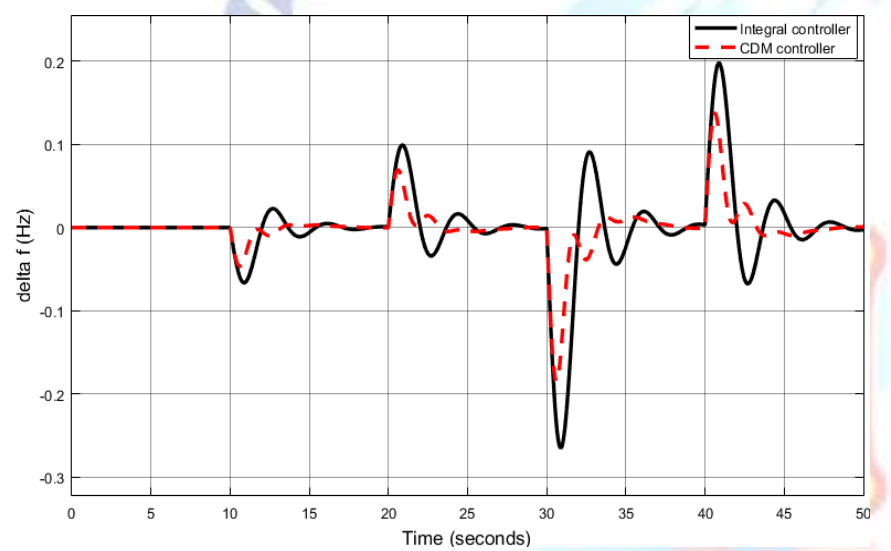

Figure 6: Frequency Deviation with Integral and CDM Controller

Table 2 compares the performance of the system using integral and CDM controller when a load disturbance of $0.02 p$.u. is given at $t=10$ seconds. It has been observed that the CDM controller gives fast and stable response when compared with integral controller.

Table2. Parameter comparison of single area system with CDM and integral controller

\begin{tabular}{|l|l|l|}
\hline Parameters & $\begin{array}{l}\text { Integral } \\
\text { control }\end{array}$ & CDM \\
\hline Rise time (sec) & 0.897 & 0.683 \\
\hline Settling time(sec) & 7.82 & 6.45 \\
\hline Peak time(sec) & 0.876 & 0.577 \\
\hline Peak value (p.u. Hz) & -0.275 & -0.19 \\
\hline
\end{tabular}

\section{CASE 2:}

The simulation of single area power system is carried out with constraints on governor and turbine with generation rate constraint (GRC) of $10 \%$ p.u. per minute. The maximum value of dead band for governor is taken as $0.05 \%$. A step load change of $\Delta \mathrm{P}_{1}=0.02$ at $\mathrm{t}=20$ seconds as shown in Figure 7 is applied to the simulation model. Figure 8 shows the simulation results of the proposed CDM controller and integral controller. The frequency deviations reach zero steady state value faster in CDM controlled when compared with integral controlled system.

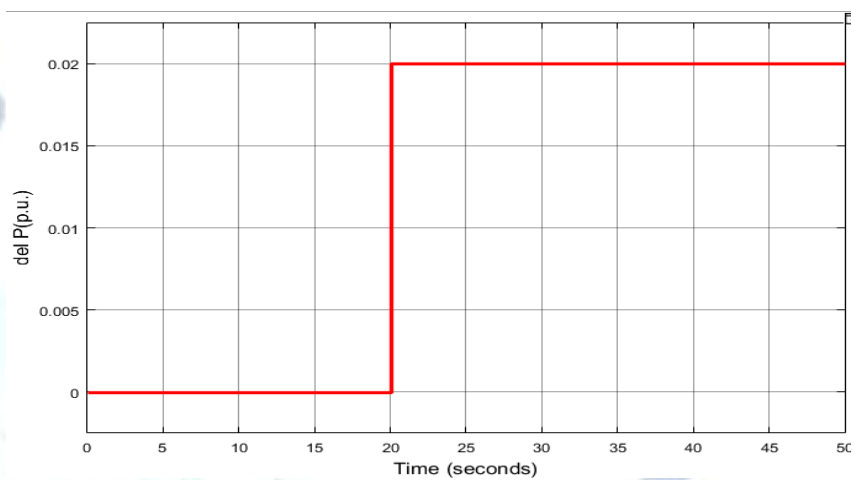

Figure 7:Load Change of 0.02p.u.

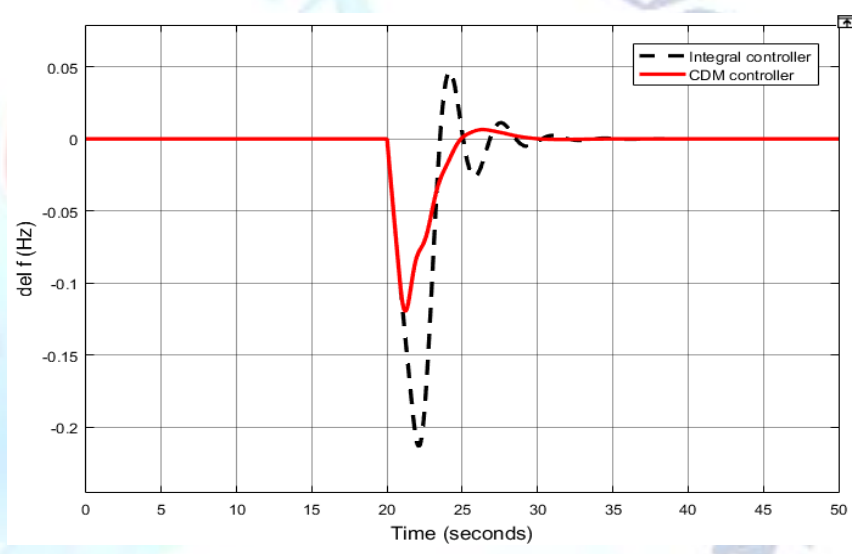

Figure 8: Frequency Deviation for Load Change of 0.02p.u.

Table3. Parameter comparison of single area system with CDM and integral controller

\begin{tabular}{|l|l|l|}
\hline Parameters & $\begin{array}{l}\text { Integral } \\
\text { control }\end{array}$ & CDM \\
\hline Rise time (sec) & 0.897 & 0.683 \\
\hline Settling time(sec) & 7.82 & 6.45 \\
\hline Peak time(sec) & 0.876 & 0.577 \\
\hline Peak value (p.u. Hz) & -0.21 & -0.12 \\
\hline
\end{tabular}

As observed from case 1 and case 2, where a single area system i.e., an islanded microgrid was subjected to load changes and the main objective of reducing the frequency deviations were achieved by using CDM controller. In order to validate the performance of CDM controller, an interconnected (two-area) system is considered for the following cases. 
CASE-3: In this scenario a two-area power system [6-8] is considered with the parameters as given in table 4. In the two-area system CDM controller is designed similar to the single area system and compared the same system with integral controller.

Here, a load disturbance of $\Delta \mathrm{P}_{1}=0.1875$ p.u. is given in the area 1 alone at $\mathrm{t}=0$ second of the simulation run time.

Table4. Parameters of Two Area Power System

\begin{tabular}{|l|l|l|l|l|l|}
\hline Area & $\begin{array}{l}\mathrm{D} \\
\text { (p.u } \\
\mathrm{Hz})\end{array}$ & $\begin{array}{l}\mathrm{H} \\
\text { (p.u.sec } \\
\text { ) }\end{array}$ & $\begin{array}{l}\mathrm{R} \\
(\mathrm{Hz} / \text { p.u.) }\end{array}$ & $\begin{array}{l}\mathrm{T}_{\mathrm{g}} \\
(\mathrm{sec})\end{array}$ & $\begin{array}{l}\mathrm{T}_{\mathrm{t}} \\
(\mathrm{sec})\end{array}$ \\
\hline 1 & 0.6 & 5 & 0.05 & 0.2 & 0.5 \\
\hline 2 & 0.9 & 4 & 0.0625 & 0.3 & 0.6 \\
\hline
\end{tabular}

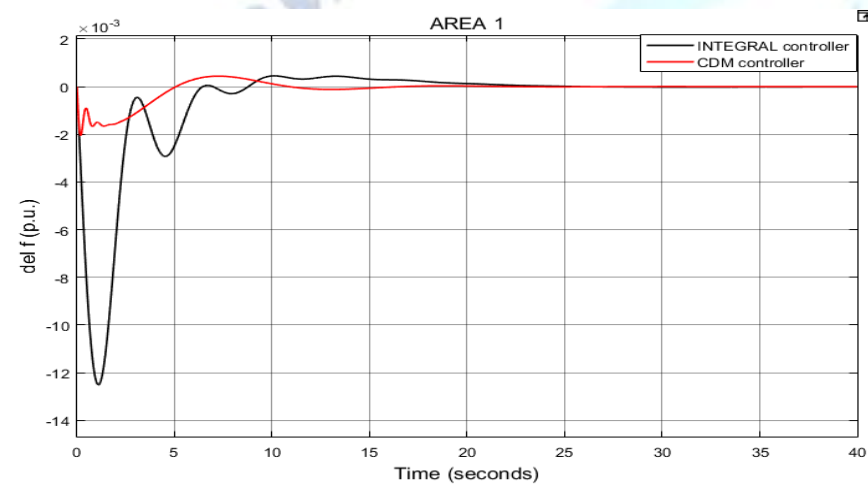

Figure 9: Frequency Deviation of Area 1 System with Integral and CDM Controller

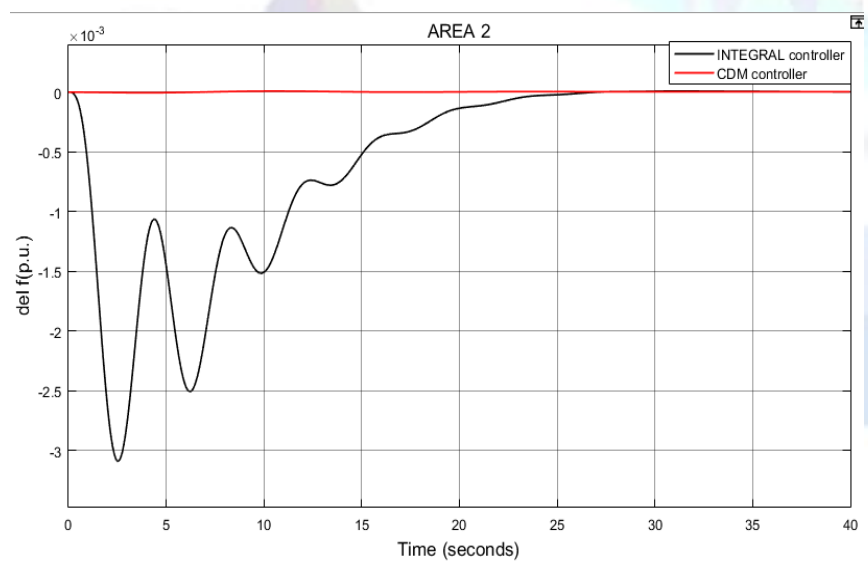

Figure 10:Frequency Deviation of Area 2 System with Integral and CDM Controller

Figure 9 and Figure 10 shows that the system response with CDM controller is faster than the integral controller. The steady state is achieved earlier by CDM than by integral controller.

Table 5 gives the comparison of performance indices of both the controllers.
Table5. Comparison of performance of both the controllers.

\begin{tabular}{|l|l|l|}
\hline Parameters & $\begin{array}{l}\text { Integral } \\
\text { control }\end{array}$ & CDM \\
\hline Rise time (sec) & 1.066 & 0.058 \\
\hline Peak time(sec) & 1.066 & 0.066 \\
\hline Peak value (p.u.Hz) & -0.01299 & -0.002 \\
\hline Settling time(sec) & 20 & 15 \\
\hline
\end{tabular}

It can be seen from the above comparison that CDM controller gives best performance when compared with integral controller.

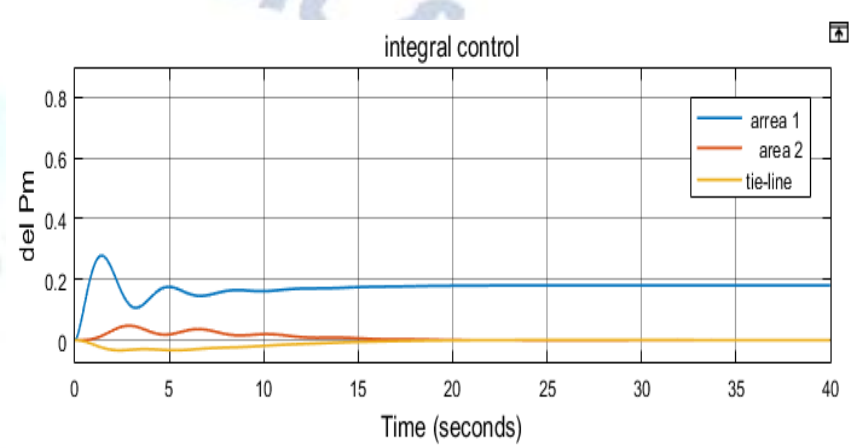

Figure 11: Change in Mechanical Power of Area 1, Area 2 and Tie Line Power with Integral Controller

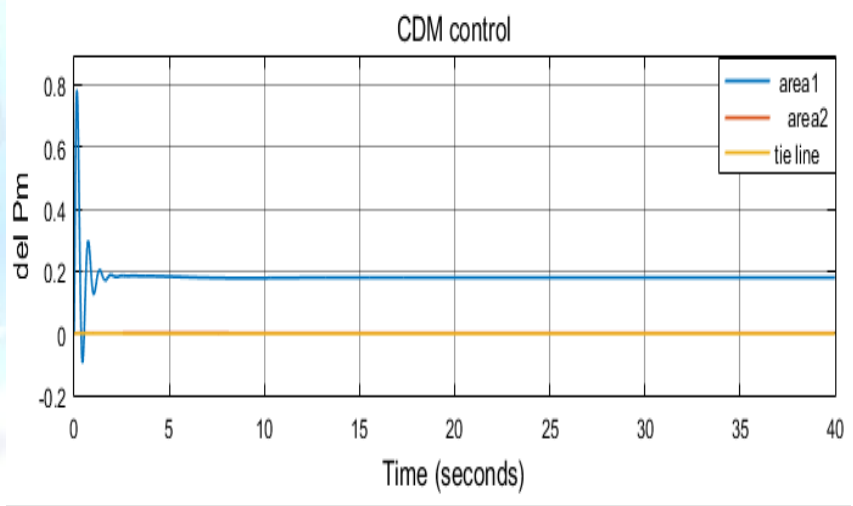

Figure 12: Change in Mechanical Power of Area1, Area2 and Tie Line Power with CDM Controller

Fig 11 and 12 shows the increase in mechanical power of area 1 , area 2 and tie-line power

A load change of 0.1875 p.u. was applied at the beginning $(\mathrm{t}=0 \mathrm{sec})$ of the simulation. It can be observed that CDM controller helps to achieve the steady state earlier when compared with integral controller.

In Figure 11 it is observed that a load change of 0.1875 p.u. is met by change in mechanical power, since area 1 is not able to achieve the increase in load demand, there is a power exchange from area 2 to 1 . Figure 12 shows the change in power for the same change in power demand steady state value is achieved quickly. 
CASE 4:

In this case, the same 2 area system is considered with a load change of 0.1 p.u. in the area 2 of the system with integral and CDM controller.

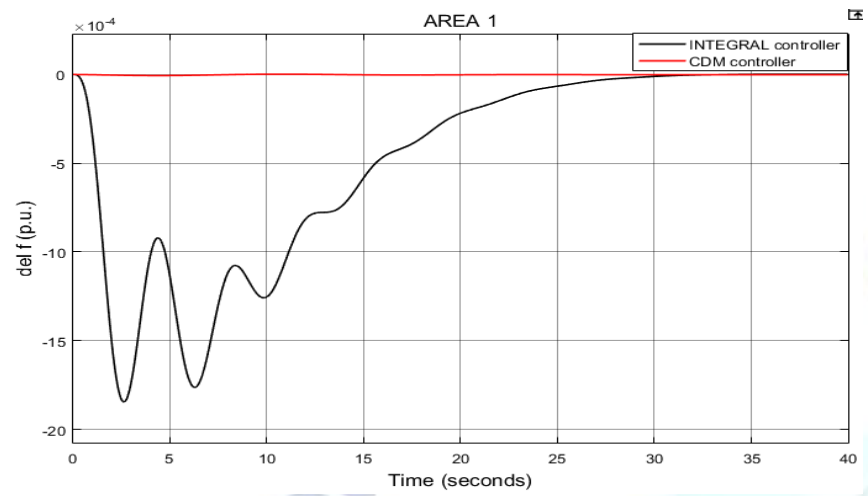

Figure 13: Frequency Deviation in Area 1 System with Integral and CDM Controller

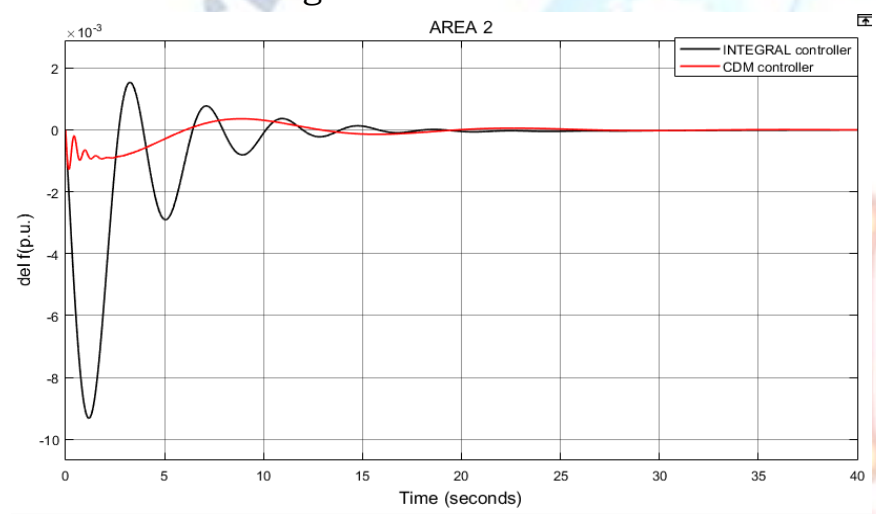

Figure 14: Frequency Deviation in Area 1 with Integral and CDM Controller

Figure 13 and 14 shows the change in frequency deviation when a load disturbance of 0.1p.u. is applied to the area 2 of the 2 -area system. It is observed that by using CDM controller, zero frequency deviation is achieved quickly and also the frequency deviation happens only in area 2 where the load disturbance is introduced. However, change in load causes frequency deviation in both the areas with integral.

Table 6 compares the performance of integral and CDM controller.

Table6. Comparison of Performance of Both the Controllers.

\begin{tabular}{|l|l|l|}
\hline Parameters & $\begin{array}{l}\text { Integral } \\
\text { control }\end{array}$ & CDM \\
\hline Rise time (sec) & 1.066 & 0.058 \\
\hline Peak time(sec) & 1.066 & 0.066 \\
\hline $\begin{array}{l}\text { Peak value }(\mathrm{Hz} \\
\text { p.u.) }\end{array}$ & -0.008 & -0.0016 \\
\hline Settling time(sec) & 20 & 17 \\
\hline
\end{tabular}

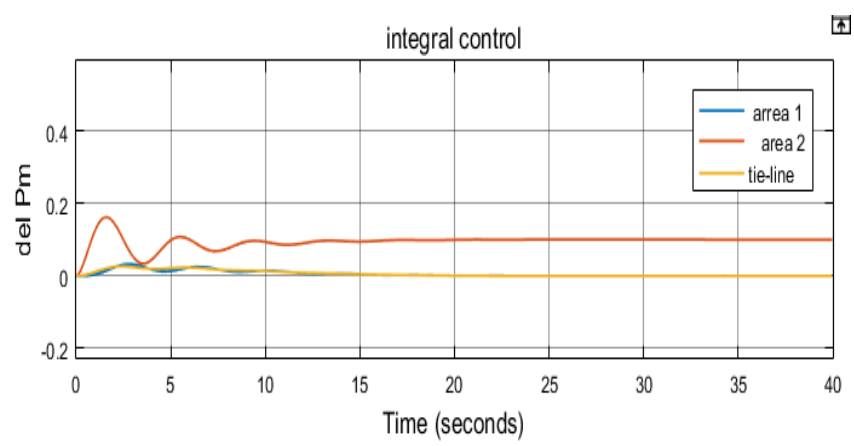

Figure 15: Change in Mechanical Power of Area1, Area 2 and Tie Line Power with Integral Controller

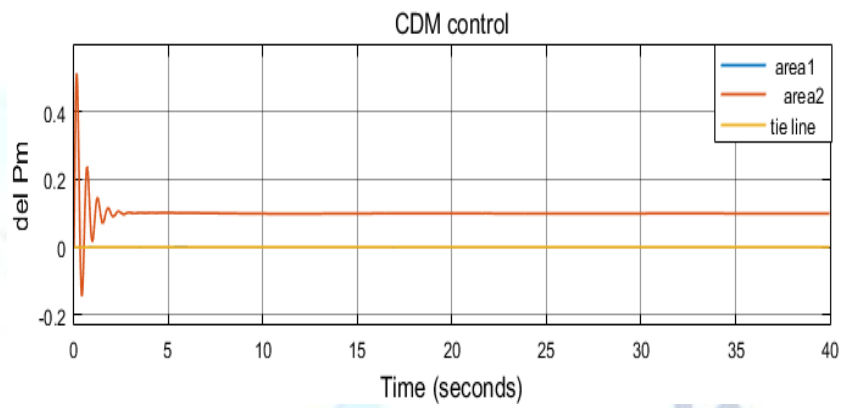

Figure 16: Change in Mechanical Power of Area1, Area2 and Tie Line Power with CDM Controller

It is observed from Figure 15 that change in power demand of 0.1 p.u. in area 1 is met by change in mechanical power in area 2, since it is not able to achieve the increase in load demand there is flow of power from area 2 to area1. Figure 16 shows the change in power for the same change in power demand and it can be seen that steady state value is achieved quickly when compared to integral controller.

\section{VI.CONCLUSION}

In this paper a load frequency controller using the Coefficient Diagram Method has been developed for single-area and two-area power systems. Simulations using MATLAB/Simulink.To validate the effectiveness of the proposed CDM controller, the power system has been tested for different load changes and parameter constraints and the performance is compared with conventional integral controller. From the simulation results it is found that the CDM controller out performs than its counterpart.

\section{REFERENCES}

[1] H. Bevrani , B. Francois and T. Ise , Microgrid Dynamics and Control, New York, USA.: IEEE -Wiley Press , 2017.

[2] B. J. Brearley, R. R. Prabu, "A Review on Isuues and Approaches for Microgrid Protection," Renewable and Sustainable Energy Reviews, vol. 67, no. 1, pp. 988-997, 2017 . 
[3] Çam E, Kocaarslan I. Load frequency control in two area power systems using fuzzy logic controller. Energy Convers Manage 2005;46:233-43.

[4] Sabahi K, Nekoui MA, Teshnehlab M, Aliyari M, Mansouri M. Load frequency control in interconnected power system using modified dynamic neural networks. In: Proceedings of the 14th mediterranean conference on control automation, Athens-Greece, July 27-29, 2007.

[5] Ali Raheel, Mohamed Tarek Hassan, Qudaih Yaser Soliman, Mitani Y. A new load frequency control approach in an isolated small power system using coefficient diagram method. Int J Electr Power Energy Syst 2014;56:110-6.

[6] J. Fang, H. Li, Y. Tang and F. Blaabjerg, "Distributed Power System Virtual Inertia Implemented by Grid-Connected Power Converters," IEEE Transactions on Power Electronics, vol. 33, no. 10, pp. 8488-8499, Oct. 2018.

[7] P. Babahajiani, Q. Shafiee and H. Bevrani, "intelligent demand response contribution in frequency control of multi-area power systems," IEEE Transactions on Smart Grid, vol. 9, no. 2, pp. 1282-1291, 2018.

[8] Lim, K. Y., Wang, Y. and Zhou, R., "Robust frequency control of multi-area power systems Transm. Distrib., Vol. 143, No. 5, pp. 377-386, 199

[9] S. Manabe, "Importance of Coefficient Diagram in Polynomial Method," in Proceedings of the 42nd IEEE Conference on Decision and Control, Maui, Hawaii USA, 2003.

[10] B. P.K, "Real Time Implementation of a New CDM-PI Control Scheme in A Conical Tank Liquid Level Maintaining System," Modern Applied Science,vol. 3, no. 5, pp. 38-45, May 2009.

[11] Bernardb MZ, Mohameda TH, Qudaihb YS, Mitanib Y.Decentralized load frequency control in an interconnected power system using Coefficient Diagram Method. Int J Electr Power Energy Syst 2014;63:165-72.

[12] T. H. Mohamed, G. Shabib and H. Ali, "Distributed load frequency control in an interconnected power system using ecological technique and coefficient diagram method," International Journal of Electrical Power \& Energy Systems, vol. 82, pp. 496-507, November 2016.

[13] Hadi Saadat. Power System Analysis.New York:Mcraw-Hill;1994

[14] N. Bigdeli, and M. Haeri, " CDM-based design and performance evaluation of a robust AQM method for dynamic TCP/AQM networks," Computer Communications, vol.32, p. 213-229, 2009.

[15] T. Kerdphol, F. S. Rahman, Y. Mitani, M. Watanabe and S. Küfeoğlu, "Robust Virtual Inertia Control of an Islanded Microgrid Considering High Penetration of Renewa ble Energy," IEEE Access,vol. 6, pp. 625-636, 2018. 